\title{
The extraperitoneal prosthetic repair of abdominal wall defects in the elderly
}

\author{
M Donati, G Brancato, S Puglia, A Donati \\ From de Senectute: Age and Health Forum \\ Catanzaro, Italy. 5-7 December 2009
}

\section{Background}

One of the most debated topics in the surgery of the abdominal wall hernias is the type and location of the prosthesis and even the employment of prosthetic materials for some authors is an object of discussion [1,2]. The aim of this work is to present the experience of a specialized center in abdominal wall surgery, showing the results of open extraperitoneal prosthetic repair of the abdominal wall defects in the elderly.

\section{Matherials and methods}

We retrospectively analyzed the 75 patients $>65$ years old admitted to our Center with a diagnosis of Incisional, Epigastric, Umbilical, Lumbar, and Spigelian hernia between January 1994 and January 2009. They were 38 males and 37 females. The diagnosis was: umbilical hernias in 6 patients, epigastric hernias in 9 patients, Spigelian hernias in 4 patients and incisional hernias in 57 patients. The comorbidities and the dimension of the defects are summarised in Figure 1 Table 1. In 42 patients we used a double-layered polipropilene mesh, in 27 a simple plug and in 4 cases a mono-layered polipropilene mesh and in 2 cases a dual-mesh. In 37 cases the mesh was placed in preperitoneal position, in 37 in premuscolar and in 2 cases in intraperitoneal. In 53 cases the surgical procedure was completed under local anaesthesia, in 22 (all incisional hernias) under general anaesthesia, no patients under spinal anaesthesia.

\section{Results}

We observed in group 6 under local anaesthesia intraoperative minor complications. Four patients referred little intraoperative pain and one medium pain. In 33 cases the

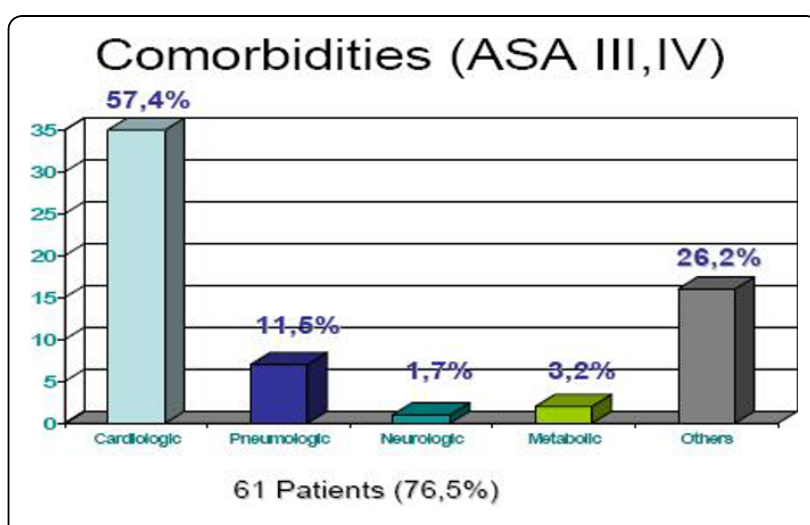

Figure 1 Distribution of main co-morbidities in the patients $>65$ years (75 Patients).

Table 1 Distribution of patients in relation to hernia's defect (size in $\mathbf{c m}$.)

\begin{tabular}{llll}
\hline Size of hernias defect & $<\mathbf{5} \mathbf{~ c m}$ & $\mathbf{5 - 1 0} \mathbf{~ c m}$ & $>\mathbf{1 0} \mathbf{~ c m}$ \\
$N$ of Patients & 40 & 25 & 10 \\
\hline
\end{tabular}

patient was discharged within 24 hours (Day Surgery). We observed no postoperative complications. In our follow-up (12-180 months) we found 3 recurrences among the incisional hernias (5,2\%), Figure 2 and 3.

\section{Conclusions}

The open extraperitoneal approach by using a polipropilene double layer mesh is in our experience the preferred technique; it almost always permits surgical repair to be carried out under local anaesthesia very often in Day Surgery [3], giving excellent long-term results and minor complications. 


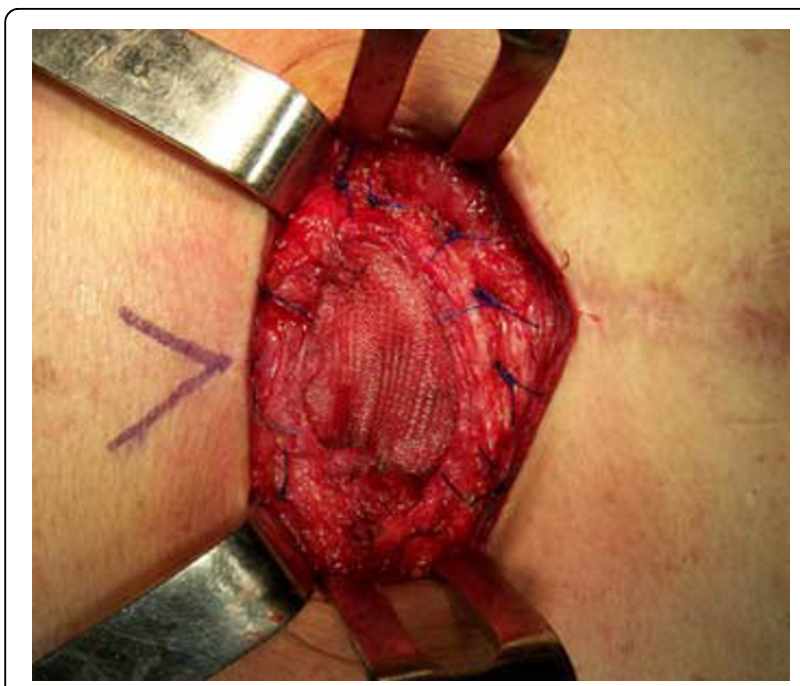

Figure 2 Epigastric Incisional hernias

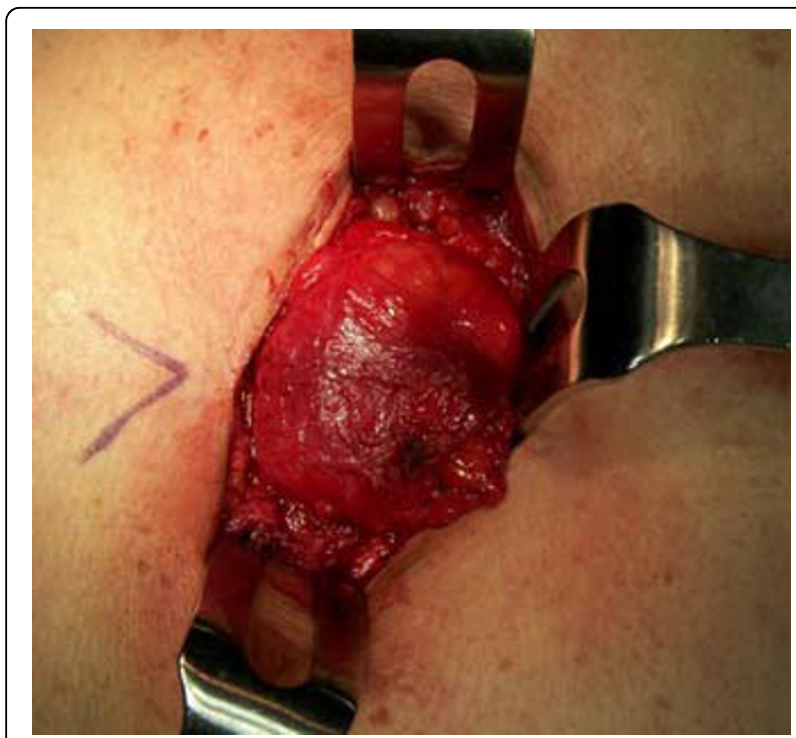

Figure 3 Extraperitoneal repair with double-layered Polipropilene mesh

Published: 19 May 2010

\section{References}

1. Diaz JJ Jr, Gray BW, Dobson JM, Grogan EL, May AK, Miller R, Guy J, O'Neill P, Morris JA Jr: Repair of giant abdominal hernias: does the type of prosthesis matter? Am. Surg. 2004, 70(5):396-401.

2. Bellon JM, Rodriguez M, Garcia-Honduvilla N, Gomez-Gil V, Pascual G, Bujan J: Comparing the behaviour of different polypropylene meshes (heavy and lightweight) in an experimental model of ventral hernia repair. J.Biomed.Mater.Res.B.Appl.Biomater 2009, 89B(2):448-55.

3. Donati M, Gandolfo L, Privitera A, Brancato G, Donati A: Day hospital for incisional hernia repair: selection criteria. Acta Chir Belg. 2008, 108(2):198-202.

doi:10.1186/1471-2318-10-S1-A6

Cite this article as: Donati et al:: The extraperitoneal prosthetic repair of abdominal wall defects in the elderly. BMC Geriatrics 2010 10(Suppl 1):A6.

\section{Submit your next manuscript to BioMed Central} and take full advantage of:

- Convenient online submission

- Thorough peer review

- No space constraints or color figure charges

- Immediate publication on acceptance

- Inclusion in PubMed, CAS, Scopus and Google Scholar

- Research which is freely available for redistribution

Submit your manuscript at www.biomedcentral.com/submit
C Biomed Central 